Research Article

\title{
Changes in the Structures and Directions of Rock Excavation Research from 1999 to 2020: A Bibliometric Study
}

\author{
Dongping Shi $\mathbb{D}^{1,2}$ Chengyu Xie $\mathbb{D}^{1},{ }^{2}$ and Lichun Xiong ${ }^{3}$ \\ ${ }^{1}$ Postdoctoral Station of Chemical Engineering and Technology, College of Chemical Engineering, Xiangtan University, \\ Xiangtan 411105, China \\ ${ }^{2}$ School of Environment and Resources, Xiangtan University, Xiang Tan 411105, China \\ ${ }^{3}$ Hunan Red Solar Photoelectricity Science and Technology Co., Ltd., Changsha 410002, China \\ Correspondence should be addressed to Chengyu Xie; xiechengyu42@xtu.edu.cn
}

Received 1 July 2021; Accepted 30 August 2021; Published 13 September 2021

Academic Editor: Jie Liu

Copyright (c) 2021 Dongping Shi et al. This is an open access article distributed under the Creative Commons Attribution License, which permits unrestricted use, distribution, and reproduction in any medium, provided the original work is properly cited.

\begin{abstract}
Rock excavation has been the hot spot and frontier of scientific research. Rock excavation research is in a period of rapid development. The bibliographies included in ISI Web of Knowledge database from 1999-2020 were used as data samples, and the collected data were analyzed by literature co-citation and cluster analysis using CiteSpace and VOSviewer information visualization techniques and dynamic network analysis tools. A knowledge map of the evolution of bibliometric research development is drawn to reveal the representative literature in the field of bibliometrics. The hot areas of bibliometric research are introduced. The development trend of bibliometrics is proposed. The results of the study show that the amount of the literature on rock excavation is growing rapidly. A large amount of the foreign literature is available in China, the United States, Australia, Canada, France, and other countries. The main included journals are Tunnelling and Underground Space Technology, International Journal of Rock Mechanics and Mining Sciences, "Rock Mechanics and Rock Engineering," "Engineering Geology," and "Bulletin of Engineering Geology and the Environment." Keyword co-occurrence analysis includes the following contents: rock damage constitutive model, excavation damage area, numerical simulation, stability analysis support, and prediction technology of rock.
\end{abstract}

\section{Introduction}

With the rapid development of underground engineering, many theories and techniques on effective rock breaking have emerged. There are various methods of rock excavation, and mechanized excavation is more widely used in underground rock engineering. With the continuous progress of science and technology, the theory of mechanical rock excavation is becoming more and more mature, and related technologies are widely used in various fields such as hydropower, mining, and transportation, bringing huge economic and social benefits $[1,2]$.

It is important to study the published research results in China, analyze the current research status and existing technical problems, in order to clarify the development context of a certain discipline. It is also useful to find future research hotspots and future research directions. There are many methods of literature research; among which scientometrics and informatics technologies have been rapidly developed in recent years, providing a reliable way for the research of the thesis data visualization. These methods make up for the shortcomings of traditional literature review research, such as insufficient reference literature and weak objective performance. The knowledge graph is a document analysis method that has emerged in recent years. Compared with the traditional research method of the review literature with reading, summary, and qualitative discussion as the main process, knowledge graph software has the advantages of large volume of literature processing, intuitive visualization, diverse analysis angles, and high reliability of data analysis results. Through a large amount of literature processing and visual analysis [3, 4], it can sort out key in- 
formation such as journals, researchers, institutions, and publication volume in a certain discipline area, summarize historical hot research directions, and predict future research directions, which are its unique functions. Most of the first scholars in China who conducted research on the application of the knowledge graph came from the information intelligence field and university libraries and other institutions.

This paper uses WOS as the data source and VOSviewer and CiteSpace visualization software as the research tools and also combines bibliometric methods to statistically and visually analyze the literature on underground engineering rock excavation from 1999 to $2020[5,6]$. In order to sort out the evolution of research hotspots and stage frontier directions in this field in the past 20 years with quantitative and visualization means, provide reference for relevant research in the field of underground engineering rock excavation.

\section{Data and Methods}

2.1. Data. The literature was sourced from the Web of Science database of the US Institute for Scientific Information (ISI), searched by TS $=$ (“rock excavation'), database $=($ SCI-EXPANDED $)$, period $=1999-2020$, document type $=($ Proceedings Paper or Article $)$, and lemmatization = open, 4568 titles were retrieved, and the operation time was June 20, 2021. TS stands for search "Topic Subject" in a Web of Science search. After filtering, matching, and reweighting, 4397 entries were obtained; each include author, institution, abstract, keywords, year of publication, issue (volume), and references. After that, the data were cleaned manually, mainly by combining near-sense words and removing generalized words to avoid affecting the analysis results.

2.2. Research Methods. There are various software tools for drawing knowledge graphs, and the most widely used ones are CiteSpace, UCINET, VOSviewer, and Global maps of science. In this paper, we mainly use two of them, VOSviewer and CiteSpace. The former, developed by Nees Janvan Eck and Ludo Waltamn, is a free bibliometric analysis and visualization software, which is powerful in "co-occurrence" network clustering and density analysis. CiteSpace was developed by Dr. Chen Chaomei from Drexel University in the United States and Dalian University of Technology, which is a Java-based citation network analysis and visualization tool for "co-citation" analysis and which is mainly used for scientific literature data measurement, analysis, and identification, as well as for displaying new trends and developments in scientific development [7-10]. In this paper, we used VOSviewer and CiteSpace software to analyze literature data visually and draw knowledge graphs to show the overall research direction, hot spots, and frontier of each historical stage of mine ecological restoration in China. At the same time, the bibliometric method was combined with literature data mining, and the type, quantity, co-authorship, and high- frequency keywords were analyzed and expressed with the help of document management software Endnote, statistical software Excel, and drawing software Origin.

\section{Results and Discussion}

3.1. Number of Articles Issued over the Years. The statistics of the chronological distribution of the number of literature can reflect the level of research and development of the field to a certain extent $[11,12]$. As shown in Figure 1, the number of literature on rock excavation shows an increasing trend with increasing years, and the growth trend is consistent with the linear regression model. It indicates that rock excavation has received more and more attention in the past 20 years, and the work of domestic scholars in this field has been strengthened and deepened, and the number of scientific achievements has increased year by year. Rock excavation research can be roughly divided into the following two development stages.

3.1.1. Initial Growth Stage (1999-2010). The annual publications are less than 50 articles/year, and the growth rate is slow, which indicates that this is the initial stage of rock excavation research development, and there are not many relevant research studies for rock excavation, and the attention and investment to this field are low.

3.1.2. Rapid Development Stage (2011-2020). The number of literature on rock excavation increased steadily from 2011 to 2020 and especially developed rapidly during 2018-2020, indicating that the field of rock excavation has attracted widespread attention from scholars and become a research hotspot.

The number of papers increased rapidly, with a total of 1,541 papers issued, accounting for $88.87 \%$ of the total, and an annual average of 220.14 papers, which is much higher than the number of papers issued in the previous two phases, and the number of papers issued in 2019 reached 469, and the total citation frequency temporarily showed a decreasing trend due to the recent time of the literature.

3.2. Country. The number of papers published and the frequency of citations reflect the overall research strength and influence of a country/region.

As shown in Table 1, China, USA, Australia, Canada, France, Turkey, Italy, Germany, Iran, and UK are the top ten international publications. The number of articles published in China is 1836, which is the highest in the world, accounting for $16.87 \%$ of all articles, followed by the number of articles published in the United States, which is 517, accounting for $15.25 \%$ of all articles; the trend of international cooperation is obviously strengthened. In terms of citation frequency, China is the first $(23,138)$, the United States is the second $(13,334)$, and Canada is the third $(8,890)$. In terms of average citations, Canada has the highest number of 29.34 citations, while China has only 12.60 citations per article. 


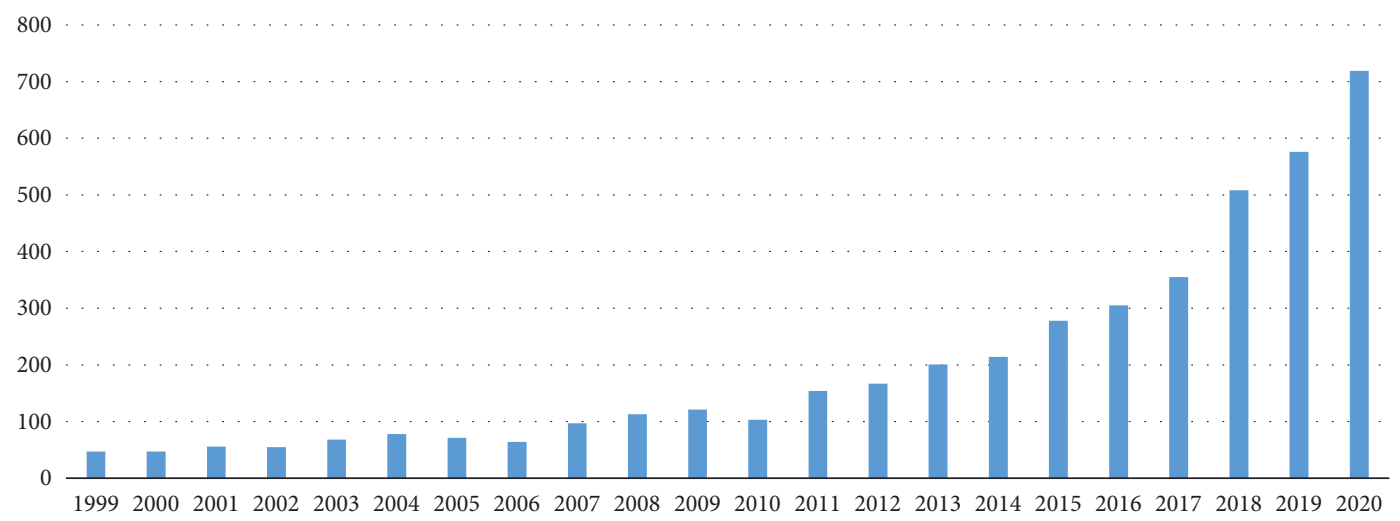

FIgURE 1: Distribution of publication during 1999-2020.

TABle 1: Top 20 research countries.

\begin{tabular}{|c|c|c|c|c|}
\hline Serial number & Country & Documents & Citations & Number of citations per article \\
\hline 1 & China & 1836 & 23138 & 12.60 \\
\hline 2 & USA & 517 & 13384 & 25.89 \\
\hline 3 & Australia & 311 & 5633 & 18.11 \\
\hline 4 & Canada & 303 & 8890 & 29.34 \\
\hline 5 & France & 247 & 5775 & 23.38 \\
\hline 6 & Turkey & 198 & 3961 & 20.01 \\
\hline 7 & Italy & 185 & 2971 & 16.06 \\
\hline 8 & Germany & 166 & 3009 & 18.13 \\
\hline 9 & Iran & 163 & 2552 & 15.66 \\
\hline 10 & England & 153 & 3421 & 22.36 \\
\hline 11 & Japan & 150 & 3610 & 24.07 \\
\hline 12 & Spain & 137 & 2313 & 16.88 \\
\hline 13 & Switzerland & 133 & 3774 & 28.38 \\
\hline 14 & South Korea & 113 & 2038 & 18.04 \\
\hline 15 & India & 104 & 1412 & 13.58 \\
\hline 16 & South Africa & 99 & 2096 & 21.17 \\
\hline 17 & Poland & 90 & 662 & 7.36 \\
\hline 18 & Sweden & 73 & 2058 & 28.19 \\
\hline 19 & Norway & 62 & 1627 & 26.24 \\
\hline 20 & Russia & 59 & 1089 & 18.46 \\
\hline
\end{tabular}

Visual analysis software of VOSviewer was used to make a map of the cooperation between countries in the world of rock excavation research for the period 1999-2020. The size of the country area in the graph indicates the active degree of a country/region and the number of publications, while the lines between countries/regions indicate the degree of cooperation between countries/regions, and more lines indicate closer cooperation between countries/regions [13, 14]. From Figure 2, it can be seen that all countries/regions cooperate closely with each other and contribute to rock excavation together; among them, the main countries that cooperate closely with other countries are China, the United States, Australia, and Canada.

3.3. Journal. The top 20 journals in terms of number of publications were statistically analyzed, which are shown in Table 2 and Figure 3. The largest number of articles is Tunnelling and Underground Space Technology, with 457 articles, 10,416 citations, and 22.79 citations per paper. The
International Journal of Rock Mechanics and Mining Sciences is the second most published journal with 368 articles, but it is the most cited journal with 13735 citations and 37.32 citations per paper $[15,16]^{\cdot}$ Although Physics and Chemistry of the Earth has only 35 articles, it has 889 citations and 25.4 citations per paper.

3.4. Institute. In terms of research institutions, Chinese Academy of Sciences has the highest number of articles (278), with 4572 citations and 16.44 citations per paper. In terms of citations, the top 5 are Chinese Academy of Sciences, China University of Mining \& Technology, Laurentian University, Northeastern University, and Wuhan Laurentian University, and the results are shown in Table 3 and Figure 4.

Although Laurentian University only ranks 12th (54 articles) in terms of published articles, it ranks 3rd in citations (3471 times), with 64.27 citations per paper. The 


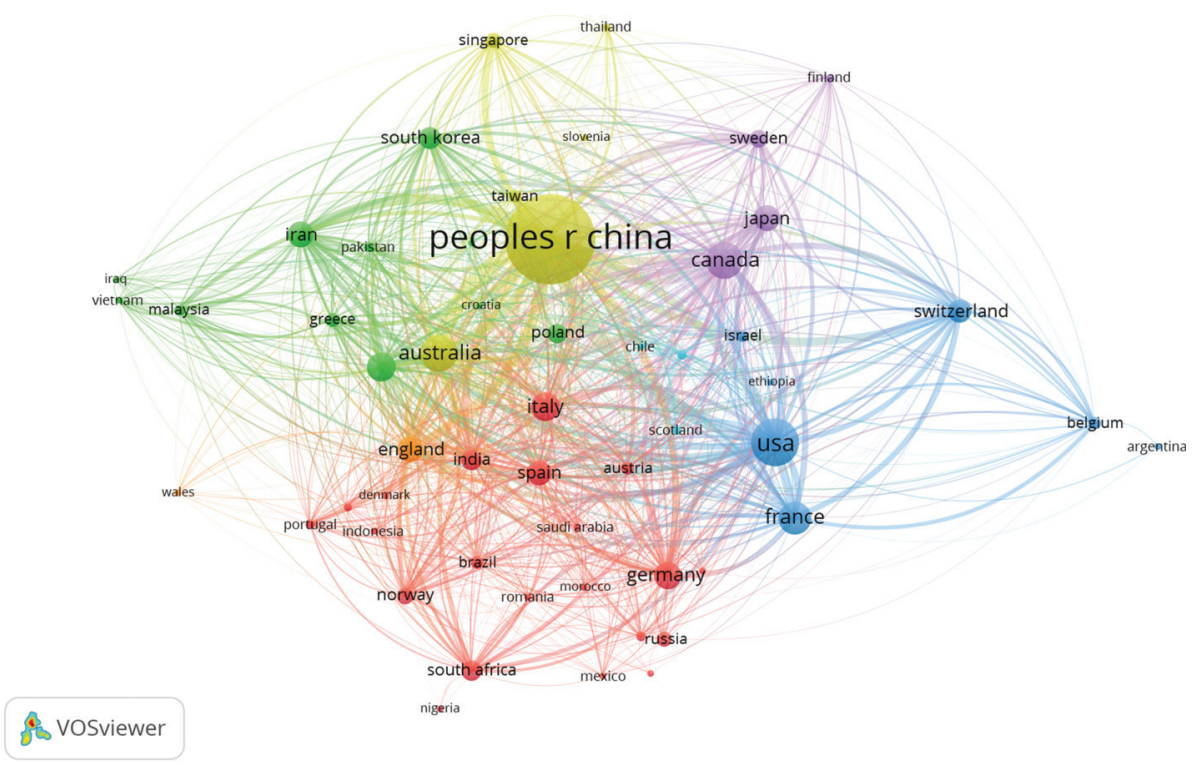

Figure 2: Map of research countries.

TABle 2: Analysis of the top 20 journal sources.

\begin{tabular}{lcccc}
\hline Rank & Periodical & Documents & Citations & Citations per paper \\
\hline 1 & Tunnelling and Underground Space Technology & 457 & 10416 & 22.79212 \\
2 & International Journal of Rock Mechanics and Mining Sciences & 368 & 13735 & 37.32337 \\
3 & Rock Mechanics and Rock Engineering & 321 & 6855 & 21.35514 \\
4 & Engineering Geology & 186 & 4840 & 26.02151 \\
5 & Bulletin of Engineering Geology and the Environment & 154 & 1516 & 9.844156 \\
6 & Advances in Civil Engineering & 124 & 284 & 2.290323 \\
7 & Arabian Journal of Geosciences & 92 & 682 & 7.413043 \\
8 & Computers and Geotechnics & 82 & 1668 & 20.34146 \\
9 & Journal of Rock Mechanics and Geotechnical Engineering & 68 & 742 & 10.91176 \\
10 & International Journal of Geomechanics & 62 & 630 & 10.16129 \\
11 & Quaternary International & 56 & 628 & 11.21429 \\
12 & Environmental Earth Sciences & 56 & 483 & 8.625 \\
13 & Geomechanics and Engineering & 55 & 352 & 6.4 \\
14 & Journal of the Southern African Institute of Mining and Metallurgy & 54 & 449 & 8.314815 \\
15 & Shock and Vibration & 49 & 127 & 2.591837 \\
16 & Journal of Mining Science & 49 & 278 & 5.673469 \\
17 & KSCE Journal of Civil Engineering & 45 & 294 & 6.533333 \\
18 & Journal of Central South University & 37 & 272 \\
19 & Physics and Chemistry of the Earth & 35 & 889 & 116 \\
20 & Archives of Mining Sciences & 33 & 25.4 \\
\hline
\end{tabular}

Chinese Academy of Sciences has the highest number of articles, but the citations per paper are low, only 15.12 .

3.5. Keywords Co-Occurrence Analysis. The keywords with high centrality play an important role as links and mediators in the keyword network mapping, and the more obvious centrality indicates the stronger control and guidance role in the whole network, which indicates that this keyword is paid attention to a high degree [17-20]. The knowledge graph of research hotspots based on the subject keywords of the literature on rock excavation research in underground engineering is shown in Figure 5. By combining and categorizing the subject keywords, it is found that the research hotspots in the field of heavy metal contaminated soil remediation technology from 1999 to 2020 are mainly focused on the following five aspects.

The red cluster focuses mainly on the rock damage constitutive model. The high-frequency keywords are constitutive model criterion, damage deform ability failure, and mechanical-behavior. The green cluster is concerned with excavation damage area. The high-frequency keywords are as follows: pressure, permeability, fractures, and hydraulic conductivity. The blue cluster presents keywords associated with numerical simulation. The high-frequency keywords are covering numerical modeling, rock mechanics, and design. The yellow cluster indicates the field of stability analysis support. The high-frequency keywords are discrete element 


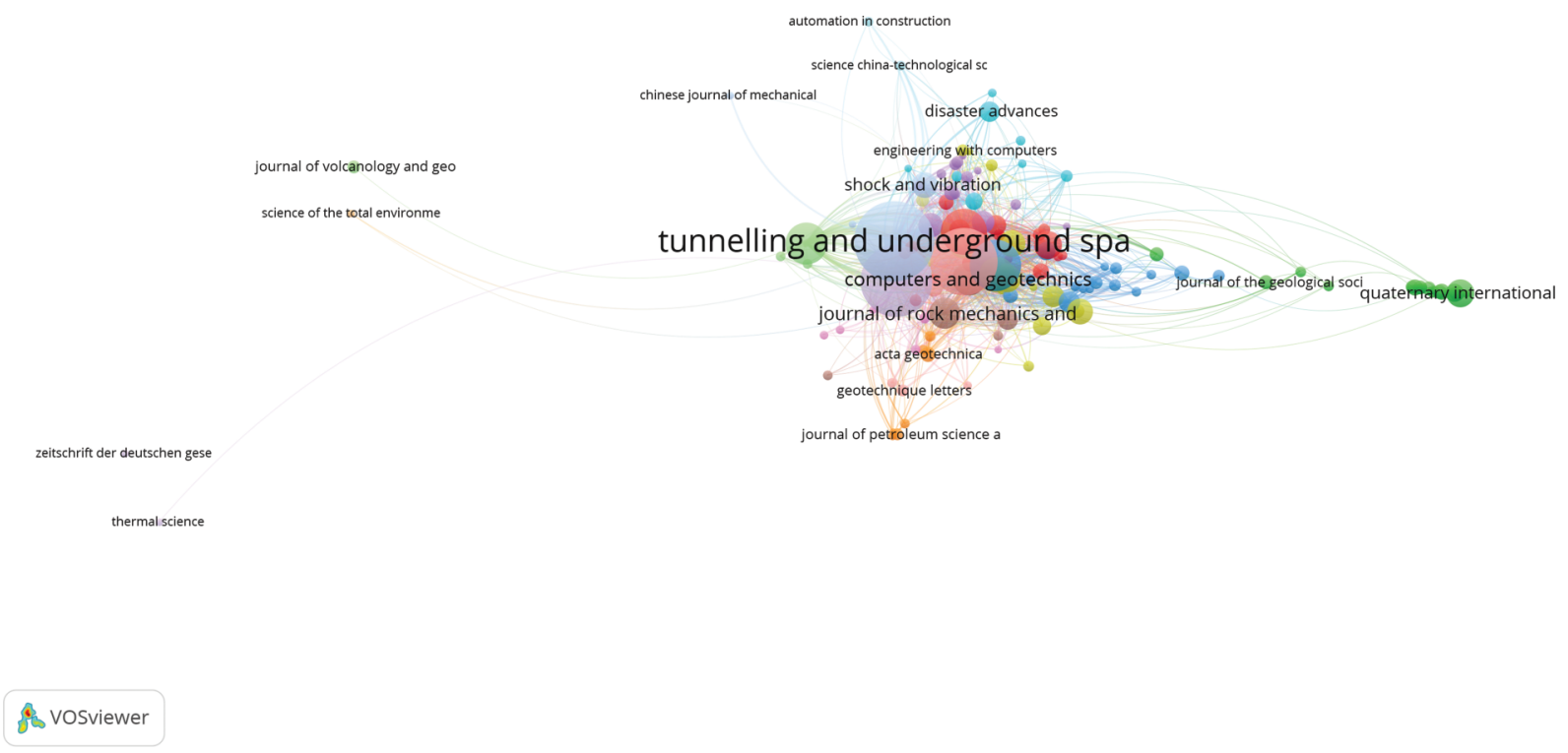

Figure 3: Map of research journal.

TABle 3: Analysis of the top 20 institutes.

\begin{tabular}{|c|c|c|c|c|}
\hline Rank & Institute & Documents & Citations & Citations per paper \\
\hline 1 & Chinese Academy of Sciences & 278 & 4572 & 16.44604 \\
\hline 2 & China University of Mining \& Technology & 269 & 3824 & 14.21561 \\
\hline 3 & Wuhan University & 134 & 1819 & 13.57463 \\
\hline 4 & Shandong University & 118 & 1455 & 12.33051 \\
\hline 5 & Northeastern University & 113 & 1825 & 16.15044 \\
\hline 6 & Central South University & 91 & 1760 & 19.34066 \\
\hline 7 & Shandong University of Science Technology & 79 & 1128 & 14.27848 \\
\hline 8 & Chongqing University & 74 & 878 & 11.86486 \\
\hline 9 & Dalian University & 65 & 1159 & 17.83077 \\
\hline 10 & Sichuan University & 63 & 757 & 12.01587 \\
\hline 11 & Colorado School of Mines & 59 & 743 & 12.59322 \\
\hline 12 & Laurentian University & 54 & 3471 & 64.27778 \\
\hline 13 & Chengdu University Technology & 54 & 312 & 5.777778 \\
\hline 14 & Monash University & 49 & 668 & 13.63265 \\
\hline 15 & Tongji University & 45 & 1063 & 23.62222 \\
\hline 16 & China University of Mining \& Technology (Beijing) & 45 & 658 & 14.62222 \\
\hline 17 & Southwest Jiaotong University & 45 & 345 & 7.666667 \\
\hline 18 & Nanyang Technology University & 44 & 1013 & 23.02273 \\
\hline 19 & University of the Witwatersrand & 44 & 996 & 22.63636 \\
\hline 20 & Politecnico di Torino & 42 & 628 & 14.95238 \\
\hline
\end{tabular}

method, rock slope, and failure mechanism. The purple cluster represents prediction technology of rock. The highfrequency keywords are as follows: prediction and rock burst.
The VOSviewer density view can show the research focus and hotspots in a certain research area by keyword density $[21,22]$. From Figure 6 , it can be seen that stability analysis 


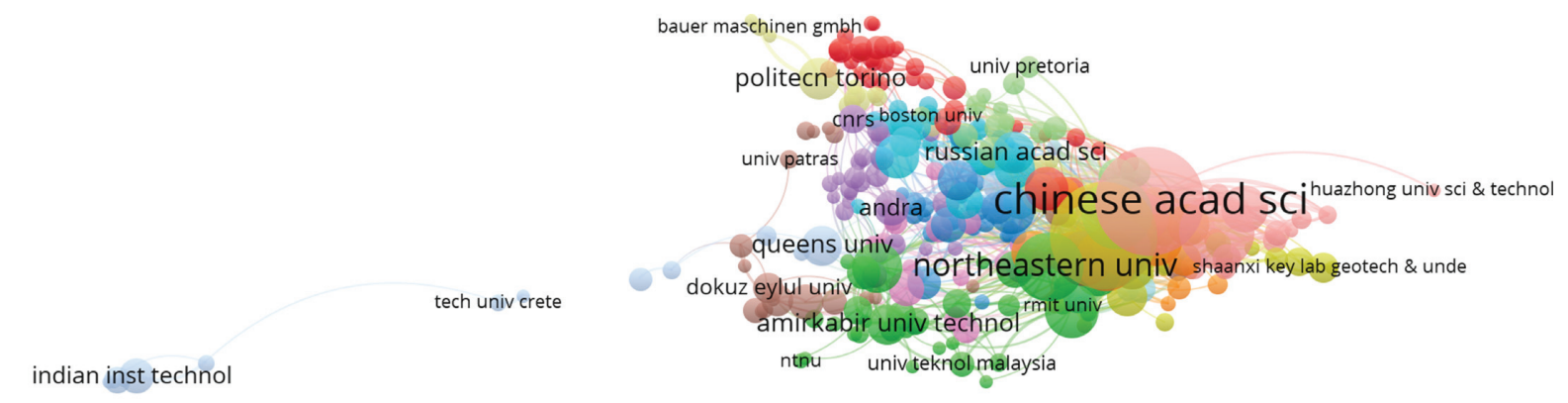

\& VOSviewer

FIgURE 4: Map of research institutes.

fes Vosviewer

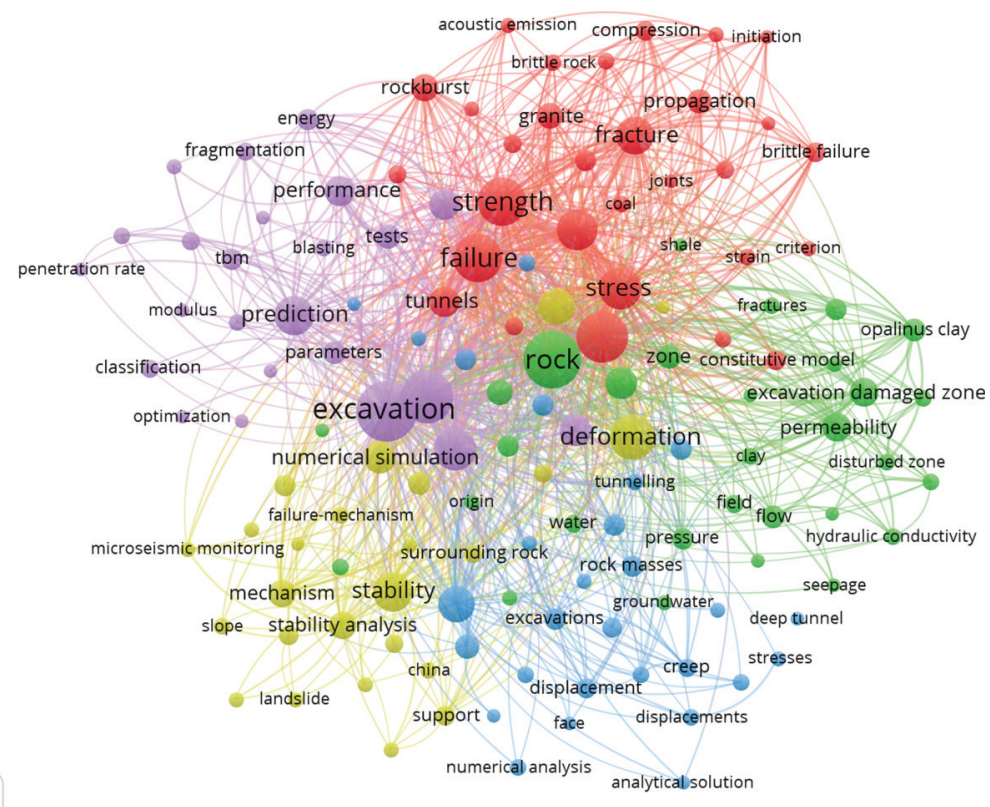

Figure 5: Co-occurrence network of keywords. 


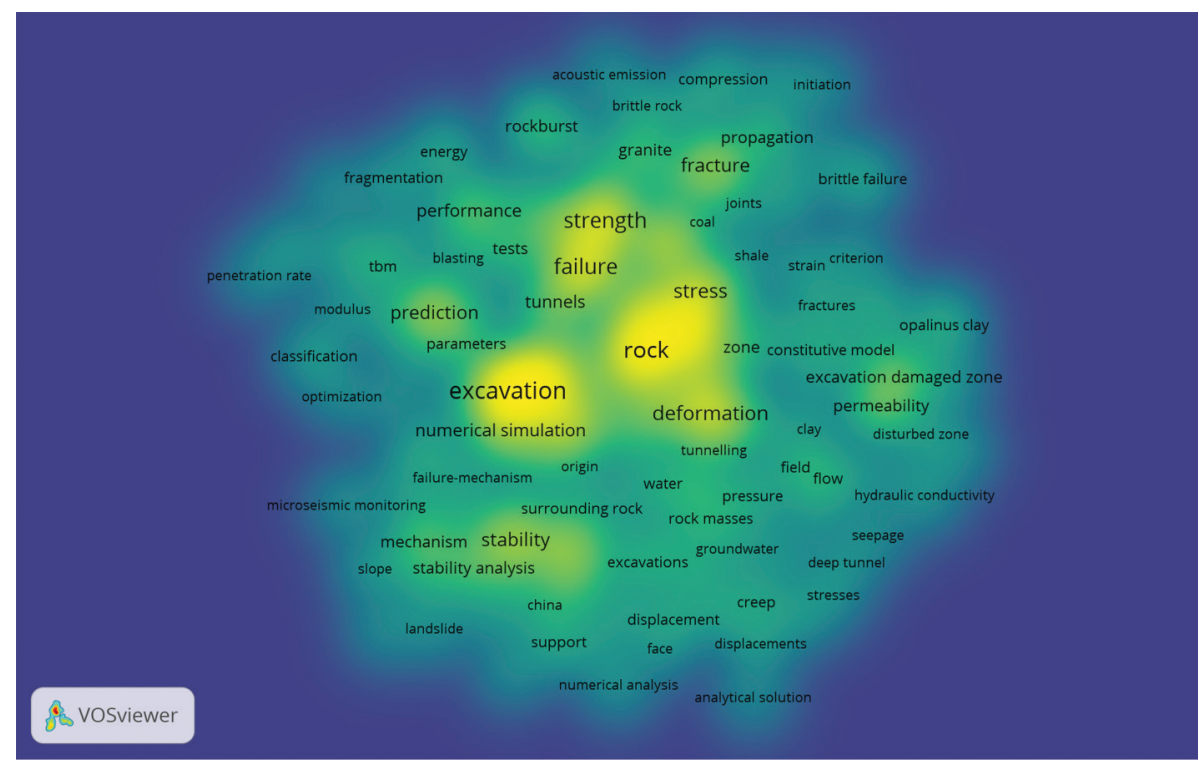

Figure 6: Hot keywords between 1999 and 2020.

and prediction are the most popular research directions in rock excavation in recent years.

\section{Conclusion}

In this study, we analyzed and visualized the graphs and related data generated from the literature about education big data in the WOS database from 1999 to 2020 through CiteSpace software at different levels, and the study came to the following conclusions:

(1) The temporal distribution spectrum shows that rock excavation research has great value, the number of research papers was relatively stable from 1999 to 2010 , but research began to emerge centrally after 2011 and entered a large-scale, rapid development phase in 2018 2020 and received widespread attention; the number of research results is abundant, and the overall trend of increasing development is on the rise, and the future expects more researchers' input and attention.

(2) The spatial distribution map shows that there are more institutions involved in rock excavation research, and the team of researchers is growing, showing the trend of "All flowers are in bloom and hundreds of schools of thoughts contend," but there is still a lack of scientific institutions and leaders with sufficient influence, and the existing research institutions are working individually, with little cooperation. In the future, we need macroguidance and establish a long-term guarantee mechanism to ensure the attention of research institutions and authors, to form a mainstream research direction, and to promote the virtuous cycle of rock excavation research.

(3) The keyword co-occurrence mapping shows that the hot spots of rock excavation research are "prediction," “stability analysis," "failure mechanism," and "mechanism." The structure of the keyword co-occurrence network is relatively loose and not high density, so researchers need to keep the research topics, research contents, and research directions in depth and increase the attention in the future.

\section{Data Availability}

The data used to support the findings of this study are included within the supplementary information files.

\section{Conflicts of Interest}

The authors declare that there are no conflicts of interest.

\section{Acknowledgments}

This research was funded by the Natural Science Foundation of Hunan Province (Grant nos. 2021JJ40538 and 2021JJ30679) and Hunan Provincial Department of Education General Project (Grant no. 18C0129).

\section{Supplementary Materials}

The supplementary data are the source data of bibliometric analysis, which contains Web of Science data for rock mechanics analysis from 1999 to 2020. (Supplementary Materials)

\section{References}

[1] M. Cardu, E. Catanzaro, A. Farinetti, D. Martinelli, and C. Todaro, "Performance analysis of tunnel boring machines for rock excavation," Applied Sciences, vol. 11, no. 6, p. 2794, 2021. 
[2] S. S. Karrari, H. J. Khademi, and T. E. Sharifi, "The assessment of rock brittleness effect on their drillability," Journal of Advanced Applied Geology, vol. 13, no. 3, 2020.

[3] F. Hassani, H. Rsffzi, and S. M. Deyps, "A review of explosicefree rock breakage(EFBR) technologies in mining industry," Selcuk University Journal of Engineering Sciences, vol. 19, no. 4, pp. 84-96, 2020.

[4] M. Heydari, S. S. Karrari, J. Khademi Hamidi, and E. Sharifi Teshnizi, "Evaluation brittleness indices of rocks, implication for estimating their toughness modulus," Scientific Quarterly Journal of Iranian Association of Engineering Geology, vol. 13, no. 3, pp. 51-65, 2020.

[5] N. J. Van Eck and L. Waltman, "Visualizing bibliometric networks," Measuring Scholarly Impact, pp. 285-320, Springer, Berlin, Germany, 2014.

[6] N. J. Van Eck and L. Waltman, "Software survey: VOSviewer, a computer program for bibliometric mapping," Scientometrics, vol. 84, no. 2, pp. 523-538, 2010.

[7] L. Waltman, N. J. Van Eck, and E. C. M. Noyons, "A unified approach to mapping and clustering of bibliometric networks," Journal of Informetrics, vol. 4, no. 4, pp. 629-635, 2010.

[8] J. M. Merigó, W. Pedrycz, and R. Weber, "Fifty years of information sciences: a bibliometric overview," Information Sciences, vol. 432, pp. 245-268, 2018.

[9] O. Ellegaard and J. A. Wallin, "The bibliometric analysis of scholarly production: how great is the impact?" Scientometrics, vol. 105, no. 3, pp. 1809-1831, 2015.

[10] M. Gutiérrez Salcedo, M. Á. Martínez, J. A. Moral Muñoz, E. Herrera Viedma, and M. J. Cobo, "Some bibliometric procedures for analyzing and evaluating research fields," Applied Intelligence, vol. 48, no. 5, pp. 1275-1287, 2018.

[11] N. K. Van, J. Li, G. Reniers, and K. Ponnet, "Bibliometric analysis of safety culture research," Safety Science, vol. 108, pp. 248-258, 2018.

[12] J. Liu and G. Jiang, "Use of laboratory indentation tests to study the surface crack propagation caused by various indenters," Engineering Fracture Mechanics, vol. 241, Article ID 107421, 2021.

[13] N. Donthu, S. Kumar, D. Mukherjee, N. Pandey, and W. M. Lim, "How to conduct a bibliometric analysis: an overview and guidelines," Journal of Business Research, vol. 133, pp. 285-296, 2021.

[14] Z. Zhao, H. Jing, X. Shi, and Y. Gao, "Experimental and numerical research on fracture behaviors of sandstone under different loading rates," Geomechanics and Geophysics for Geo-Energy and Geo-Resources, vol. 6, no. 4, pp. 1-17, 2020.

[15] J. Liu, Y. Liu, Y. Zhu et al., "Study of influences of rock hardness on crack evolution rule under hydraulic fracturing," Proceedings of the Conference Series: Earth and Environmental Science, vol. 558, no. 3, Article ID 032003, 2020.

[16] Z. Zhang, F. Chen, C. Zhang et al., "Numerical simulation of rock failure process with a 3D grain-based rock model," Advances in Civil Engineering, vol. 2020, Article ID 8810022, 11 pages, 2020.

[17] C. Kumar, L. A. Kumaraswamidhas, V. M. S. R. Murthy, and A. Prakash, "Experimental investigations on thermal behavior during pick-rock interaction and optimization of operating parameters of surface miner," International Journal of Rock Mechanics and Mining Sciences, vol. 133, Article ID 104360, 2020.

[18] A. Ramezanzadeh and M. Hood, "A state-of-the-art review of mechanical rock excavation technologies," Journal of Mining and Environment, vol. 1, no. 1, 2010.
[19] A. Prakash, V. M. S. R. Murthy, and K. B. Singh, "Rock excavation using surface miners: an overview of some design and operational aspects," International Journal of Mining Science and Technology, vol. 23, no. 1, pp. 33-40, 2013.

[20] J. Liu, J. Wang, and W. Wan, "Numerical study of crack propagation in an indented rock specimen," Computers and Geotechnics, vol. 96, pp. 1-11, 2018.

[21] M. A. Karasev, R. O. Sotnikov, V. Y. Sinegubov, N. A. Egorova, K. V. Makarov, and A. I. Thorikov, "Development of a model for predicting the dynamic effect on the stability of rock excavation," Journal of Physics: Conference Series, vol. 1384, no. 1, Article ID 012051, 2019.

[22] K. Randhawa, R. Wilden, and J. Hohberger, "A bibliometric review of open innovation: setting a research agenda," Journal of Product Innovation Management, vol. 33, no. 6, pp. 750772, 2016. 